\title{
COMPOSIÇÃO QUÍMICA, VITREOSIDADE E DIGESTIBILIDADE DE DIFERENTES HÍBRIDOS DE MILHO PARA SUÍNOS ${ }^{1}$
}

\author{
Chemical composition, vitreousity endosperm and digestibility of different \\ hybrids of corn for growing pigs
}

\author{
Vinícius de Souza Cantarelli², Elias Tadeu Fialho ${ }^{3}$, Raimundo Vicente de Sousa ${ }^{4}$, \\ Rilke Tadeu Fonseca de Freitas ${ }^{3}$, José Augusto de Freitas Lima ${ }^{3}$
}

\begin{abstract}
RESUMO
Objetivou-se avaliar a composição química, vitreosidade e valores nutricionais de diferentes híbridos de milho através de análises laboratoriais e de um ensaio de metabolismo com suínos em crescimento. Foram utilizados 24 suínos em fase de crescimento (35,6 Kg $\pm \pm 3,05 \mathrm{~kg}$ de PV) machos castrados mestiços (LD x LW), os quais foram mantidos em gaiolas de metabolismo e distribuídos em um delineamento inteiramente ao acaso totalizando 24 parcelas. Os tratamentos experimentais consistiram de 6 rações com os seguintes híbridos de milho: milho óleo (Móleo), milho QPM (MQPM), milho dentado (Mdent), milho semidentado (Msemi) e dois milhos duros (Mdur1) e (Mdur2). Os valores obtidos de vitreosidade, coeficiente de digestibilidade da proteína bruta (CDPB) e energia digestível (ED) para Móleo, MQPM, Mdent, Msemi, Mdur1 e Mdur2 foram 78,5\%; 71,7\%; 57,2\%; 68,2\%; 75,9\%; 82,8\%; $81,68 \% ; 80,14 \% ; 82,35 \% ; 69,71 \% ; 76,98 \% ; 75,61 \% ; 3680 ; 3426 ; 3597 ; 3441 ; 3340$ e $3469 \mathrm{Kcal} / \mathrm{Kg}$, respectivamente. Foram observadas diferenças significativas $(\mathrm{P}<0,05)$ para os valores de vitreosidade, mostrando que os milhos de textura dura apresentam maior vitreosidade em relação ao semidentado e ao dentado. Houve diferenças significativas no CDMS, CDPB e ED entre os milhos estudados $(\mathrm{P}<0,05)$, mostrando que o milho óleo (Móleo) e o dentado (Mdent) foram superiores aos demais. Em relação ao nitrogênio retido $(\% \mathrm{NR})$, houve diferenças significativas $(\mathrm{P}<0,05)$ entre os milhos estudados. Para esta variável os milhos dentado, QPM e alto óleo mostraram-se superiores aos milhos semidentado e os duros. Conclui-se que os milhos dentado, Móleo e MQPM foram superiores aos demais.
\end{abstract}

Termos para indexação: Vitreosidade , corn endosperma, ensaios metabolicos, suínos.

\begin{abstract}
This study was conducted in order to evaluate the chemical composition, vitreousity endosperm and nutritional values of different hybrids of corn through of chemical analysis and a metabolism assay with growing pigs. The metabolism assay were conducted by utilizing 24 crossbred (LD x.LW) barrows with $35,6 \mathrm{Kg}+-3,05 \mathrm{Kg}$ keept in metabolism cages . The experimental treatments were formed by six (6) diets formulated with hybrids of corn: "corn oil", corn QPM, corn-dent, semi-dent, and two cornsflints. The values obtained Vitreousity, Digestibility Coefficients of the Crude Protein, and Energy Digestible for corns high oil, QPM, dent, semi-dent, hard 1 and hard 2 were $78,5 \% ; 71,7 \% ; 57,2 \% ; 68,2 \% ; 75,9 \% ; 82,8 \% ; 80,14 \% ; 82,35 \% ; 69,71 \% ; 76,98 \%$; $75,61 \% ; 3680,3426 ; 3597 ; 3441 ; 3340$ and $3469 \mathrm{Kcal} / \mathrm{Kg}$, respectively. The data shown significant differences $(\mathrm{P}<0,005)$ for the values of vitreousity $(\mathrm{P}<0,005)$ among the corns studied. Corns varieties with hard texture show a higher vitreousity as compared with those semi-dent and corn dent varieties. There were significant differences in Digestibility Coefficients of Dry Matter, Digestibility Coefficients of Protein Crude and Energy Digestible among the corn varieties studied $(\mathrm{P}<0,05)$. The "corn oil" and the corn dent varieties shown higher digestibility values than others. The Nitrogen Retention showed significant differences $(P<0,05)$ among the corns studied. The corns varieties dent, QPM and "corn oil" showed higher digestibility as compared with the semi-dent and corns-flints varieties. In conclusion the corn-dent, "corn oil"and corn QPM varieties showed better nutritional values than others varieties studied.
\end{abstract}

Index terms: Metabolism assay, vitreous endosperm, pigs.

(Recebido em 2 de março de 2004 e aprovado em 27 de março de 2006)

\section{INTRODUÇÃO}

O milho representa a maior fonte de energia na dieta dos suínos e uma importante fonte de aminoácidos. Em combinação com o farelo de soja, vitaminas e minerais, resulta em dietas que são consideradas nutricionalmente bem balanceadas para suínos em crescimento e terminação.
A produção brasileira de milho nas safras 2001/2002 e 2002/2003 fecharam com uma produção em torno de 40 milhões de toneladas, sendo que a suinocultura demanda aproximadamente $25 \%$ desta produção.

No custo de produção dos suínos, o principal componente é a alimentação dos animais, sendo o milho, o ingrediente que mais contribui para o alto custo das rações,

\footnotetext{
Parte da Dissertação apresentada à UFLA, pelo primeiro autor para obtenção do grau de mestre em Zootecnia.

2 Doutor em Nutrição Animal, aluno de doutorado da Universidade Federal de Lavras/UFLA - Cx. P. 3037 - 37200-000 - Lavras, MG

${ }^{3}$ Professores do Departamento Zootecnia da Universidade Federal de Lavras/UFLA - Cx. P. 3037 - 37200-000 - Lavras, MG.

${ }^{4}$ Professor do Departamento de Medicina Veterinária da Universidade Federal de Lavras/UFLA - Cx. P. 3037 - $37200-000$ - Lavras, MG.
} 
principalmente em épocas de baixa oferta deste grão. Normalmente este grão é tratado como um ingrediente de composição química conhecida e padronizada, estabelecida pela média de valores e publicada em tabelas de composição de alimentos. No entanto, ocorre variação significativa nestes valores, ou seja, na composição química do milho. Estas variações tem sido observadas em diferentes pesquisas no Brasil. Levantamentos da EMBRAPA/CNPSA mostram grandes diferenças na composição dos híbridos comercializados, com valores de óleo, de 2,87 a 6,87\%, de proteína bruta, de 7,18 a $13,66 \%$, e energia digestível de 3211 a $3567 \mathrm{Kcal} / \mathrm{Kg}$ (LIMA, 2001).

Nos últimos anos com o advento da engenharia genética, as companhias multiplicadoras de sementes estão alterando seus programas para aumentar o valor nutricional do milho para suínos e aves. Os novos híbridos de milho são referidos como "especiais" ou de "valor adicional" ou "nutricionalmente melhores" que proporcionam características úteis para a produção de suínos (HOUSE, 1997). Porém, outras características devem ser revistas em relação ao valor nutricional dos milhos normalmente utilizados na alimentação animal. Uma delas é a textura do grão, que normalmente é usada como ferramenta em questões agronômicas, mas por outro lado pode ter efeitos importantes no valor nutricional dos híbridos de milho.

Em relação à textura do grão, este pode ser classificado como duro, dentado, semidentado ou semiduro, sendo a vitreosidade, um parâmetro importante para avaliar com maior precisão a textura do grão, em virtude de estar relacionada com a quantidade de endosperma vítreo e farináceo, ou seja, quanto mais duro o grão, maior a quantidade de endosperma vítreo, por outro lado, quanto mais dentado o grão, maior a quantidade de endosperma farináceo. A questão é que a vitreosidade apresenta valor numérico, que é resultado da relação entre endosperma vítreo e endosperma total (CORRÊA, 2001). Se considerarmos que o endosperma vítreo apresenta uma certa resistência à atuação das enzimas digestivas, a relação deste com o endosperma farináceo pode afetar diretamente a digestibilidade do milho.

Neste sentido, objetivou-se com o presente trabalho, determinar se a vitreosidade e a composição química de diferentes híbridos de milho pode afetar a digestibilidade e o valor nutricional destes grãos.

\section{MATERIAL E MÉTODOS}

O experimento foi conduzido no DZO/UFLA. Foram usados 24 suínos machos castrados alojados individualmente em gaiolas de metabolismo. O delineamento experimental foi inteiramente ao acaso, com 24 parcelas representadas pelos animais que foram utilizados no ensaio de metabolismo constituindo-se de 6 tratamentos e 4 repetições. Os tratamentos experimentais consistiram de 6 dietas (Tabela 1) que continham, cada uma, um híbrido de milho diferente. Os milhos testados foram: milho alto óleo (Móleo), milho QPM (MQPM), um milho dentado (Mdent), um milho semidentado (Msemi) e dois milhos duros (Mdur1) e (Mdur2).

Antes de serem incorporados à ração, os grãos de milho passaram por um processo de limpeza convencional, para evitar contaminantes que pudessem mascarar o valor nutricional dos grãos, além de serem moídos em peneira de $2 \mathrm{~mm}$. Os procedimentos metodológicos para o ensaio de metabolismo foram realizados de acordo com o descrito por Fialho et al. (1979). As variáveis analisadas foram Vitreosidade pelo método de dissecação manual dos grãos (DOMBRINKKURTZMAN \& BIETZ, 1993). Como a vitreosidade dos grãos varia, dependendo de sua posição na espiga (PRATT et al., 1995), o seguinte procedimento foi adotado para minimizar esse efeito: 100 grãos de cada híbrido foram selecionados aleatoriamente e divididos em 10 grupos, visualmente homogêneos em tamanho e forma do grão. A vitreosidade foi determinada em um grão de cada grupo selecionado aleatoriamente. Após imersão em água destilada por 3 minutos, os grãos foram secos com papel toalha e o pericarpo e o germe, removidos com bisturi. O que sobrou após a retirada do germe e do pericarpo, foi o endosperma, que foi, então, pesado (endosperma total). Em seguida, o endosperma farináceo foi manualmente removido usando o bisturi, e o peso do endosperma vítreo restante foi expresso como porcentagem do endosperma total; Composição Química, que foram analisados o conteúdo de matéria seca, proteína bruta, extrato etéreo e energia de acordo com AOAC (1995); e no ensaio de metabolismo foram Coeficiente de Digestibilidade da Matéria Seca (CDMS), Coeficiente de Digestibilidade da Proteína Bruta (CDPB), Porcentual de Nitrogênio Retido ( $\% \mathrm{NR}$ ) e Energia Digestível (ED). Os dados referentes aos tratamentos foram submetidos à análise de variância segundo o teste Tukey segundo o pacote estatístico SAS Institute (1985). 
TABELA 1 - Composição centesimal e valores analisados e calculados das rações experimentais.

\begin{tabular}{|c|c|c|c|c|c|c|}
\hline \multirow{2}{*}{ Ingrediente } & \multicolumn{6}{|c|}{ Tratamento $^{1}$} \\
\hline & Móleo & MQPM & Mdent & Msemi & Mdur1 & Mdur2 \\
\hline Milho óleo & 96,75 & - & - & - & - & - \\
\hline Milho QPM & - & 96,75 & - & - & - & - \\
\hline Milho dentado & - & - & 96,75 & - & - & - \\
\hline Milho semidentado & - & - & - & 96,75 & - & - \\
\hline Milho duro 1 & - & - & - & - & 96,75 & - \\
\hline Milho duro 2 & - & - & - & - & - & 96,75 \\
\hline Calcário calcítico & 1,2 & 1,2 & 1,2 & 1,2 & 1,2 & 1,2 \\
\hline Fosfato bicálcio & 1,5 & 1,5 & 1,5 & 1,5 & 1,5 & 1,5 \\
\hline Sal iodado & 0,4 & 0,4 & 0,4 & 0,4 & 0,4 & 0,4 \\
\hline Premix Vit./ Min. ${ }^{1}$ & 0,15 & 0,15 & 0,15 & 0,15 & 0,15 & 0,15 \\
\hline \multicolumn{7}{|l|}{ Valores analisados } \\
\hline MS $\%^{2}$ & 90,18 & 88,65 & 88,08 & 88,21 & 88,04 & 88,51 \\
\hline $\mathrm{PB} \%^{2}$ & 9,92 & 9,75 & 9,45 & 7,69 & 9,78 & 9,43 \\
\hline $\mathrm{EE} \%^{2}$ & 5,57 & 3,89 & 4,16 & 3,57 & 3,92 & 4,08 \\
\hline \multicolumn{7}{|l|}{ Valores Calculados } \\
\hline Lisina total & 0,31 & 0,36 & 0,27 & 0,21 & 0,28 & 0,27 \\
\hline $\mathrm{Ca}$ & 0,03 & 0,037 & 0,03 & 0,03 & 0,03 & 0,03 \\
\hline $\mathrm{Pt}$ & 0,24 & 0,20 & 0,24 & 0,24 & 0,24 & 0,24 \\
\hline $\mathrm{Pd}$ & 0,08 & 0,07 & 0,08 & 0,08 & 0,08 & 0,08 \\
\hline
\end{tabular}

${ }^{1}$ Móleo-(milho alto óleo); MQPM-(milho alta lisina); Mdent-(milho dentado); Msem-(milho semidentado); Mdur1 e Mdur2 (milhos duros).

${ }^{2}$ Análises realizadas no Laboratório de Nutrição Animal do Departamento de Zootecnia da UFLA.

\section{RESULTADOS E DISCUSSÃO}

Os valores de composição em matéria seca (MS), proteína bruta $(\mathrm{PB})$ e extrato etéreo (EE) dos diferentes milhos estudados encontram-se na Tabela 2.

Os valores de matéria seca foram semelhantes entre os híbridos de milho. Para os valores de proteína bruta (PB), também houve semelhança entre os híbridos estudados, exceto para milho semidentado (Msemi) que apresentou valor inferior comparado com os outros milhos. Os valores de extrato etéreo (EE), exceto o milho alto óleo, também apresentaram semelhança. Mesmo apresentando ligeiras variações numéricas, estes valores estão de acordo com o banco de dados analisados no Laboratório de Análises Físico Químicas da EMBRAPA/CNPSA no período de 1979 e 1997, quando foi observado variação nos valores de óleo, de 1,41\% a 6,09\%, e nos valores de proteína, de 6,43\% a 10,99\% (LIMA, 2001).

Os valores de vitreosidade do endosperma dos milhos usados nas rações são apresentados na Tabela 3.
Foi observada diferença significativa $(\mathrm{P}<0,05)$ nos valores de vitreosidade, mostrando que os milhos de textura dura apresentam maior vitreosidade em relação ao semidentado e o dentado. Este resultado está similar aos estudados por Corrêa (2001), que analisou grãos de milhos brasileiros com textura vítrea (duro) e americanos com textura mole (dentado), e observou maior vitreosidade nos milhos brasileiros $(73,2 \%)$ em relação aos americanos $(47 \%)$.

Em relação a vitreosidade do milho alto óleo e o QPM utilizado neste estudo, observou-se uma diferença significativa $(\mathrm{P}<0,05)$ entre os híbridos, sendo que o alto óleo mostrou ter um endosperma mais vítreo que o QPM. Os valores de matéria seca digestível (CDMS), coeficiente de digestibilidade da proteína bruta (CDPB), energia digestível (ED) e porcentagem de nitrogênio retido (\%NR) dos híbridos testados são apresentados na Tabela 4. 
TABELA 2 - Composição em matéria seca (MS), proteína bruta (PB) e extrato etéreo (EE) dos milhos usados no experimento.

\begin{tabular}{lcccccc}
\hline \multicolumn{7}{c}{ Milhos } \\
\hline Composição & Móleo & MQPM & Mdent & Msemi & Mdur1 & Mdur2 \\
\hline MS $(\%)^{2}$ & 90,18 & 88,65 & 88,08 & 88,21 & 88,04 & 88,51 \\
PB $(\%)^{2}$ & 9,92 & 9,75 & 9,45 & 7,69 & 9,78 & 9,43 \\
EE $(\%)^{2}$ & 5,57 & 3,89 & 4,16 & 3,57 & 3,92 & 4,08 \\
\hline
\end{tabular}

${ }^{1}$ Valores expressos em base de matéria natural.

${ }^{2}$ Análises realizadas no Laboratório de Nutrição Animal do Departamento de Zootecnia da UFLA.

TABELA 3 - Valores de vitreosidade do endosperma dos híbridos de milhos testados no presente experimento.

\begin{tabular}{cc}
\hline Milhos & Vitreosidade $^{1}$ \\
\hline Móleo & $78,5 \mathrm{ab}$ \\
MQPM & $71,7 \mathrm{dc}$ \\
Mdent & $57,2 \mathrm{e}$ \\
Msemi & $68,2 \mathrm{~d}$ \\
Mdur1 & $75,9 \mathrm{bc}$ \\
Mdur2 & $82,8 \mathrm{a}$ \\
\hline CV\% & 2,44 \\
\hline
\end{tabular}

${ }^{1}$ Valores seguidos de letras diferentes na mesma linha diferem para $\mathrm{P}<0,05$ (Tukey).

TABELA 4 - Coeficiente de digestibilidade da matéria seca (CDMS), coeficiente de digestibilidade da proteína bruta (CDPB), energia digestível (ED) e porcentagem de nitrogênio retido (\%NR) das rações formuladas com diferentes híbridos de milho.

\begin{tabular}{|c|c|c|c|c|c|c|c|}
\hline \multirow[b]{2}{*}{ Variável $^{1}$} & \multicolumn{6}{|c|}{ Tratamentos } & \multirow[b]{2}{*}{ CV $(\%)$} \\
\hline & Móleo & MQPM & Mdent & Msemi & Mdur1 & Mdur2 & \\
\hline CDMS (\%) & $88,13 a$ & $85,60 \mathrm{~b}$ & $88,79 a$ & $85,91 \mathrm{~b}$ & $84,98 b$ & $85,86 b$ & 0,95 \\
\hline CDPB $(\%)$ & $81,68 \mathrm{a}$ & $80,14 \mathrm{ab}$ & $82,35 \mathrm{a}$ & $69,71 d$ & $76,98 \mathrm{bc}$ & $75,61 \mathrm{c}$ & 2,28 \\
\hline $\mathrm{ED}(\mathrm{Kcal} / \mathrm{Kg})^{2}$ & $3680 \mathrm{a}$ & $3426 b c$ & $3597 a$ & $3441 b c$ & $3340 \mathrm{c}$ & $3469 b$ & 1,37 \\
\hline$\% \mathrm{NR}$ & $49,05 \mathrm{abc}$ & $54,96 \mathrm{ab}$ & $58,36 \mathrm{a}$ & $41,27 \mathrm{c}$ & $46,25 b c$ & $42,22 \mathrm{c}$ & 9,44 \\
\hline
\end{tabular}

${ }^{1}$ Valores seguidos de letras diferentes na mesma linha diferem para $\mathrm{P}<0,05$ (Tukey).

${ }^{2}$ Valores expressos com base na matéria natural.

Houve diferença significativa no CDMS, CDPB, ED e \%NR entre os milhos estudados $(\mathrm{P}<0,05)$, sendo que o milho alto óleo (Móleo) e o dentado (Mdent) mostraramse superiores aos demais. Esta melhora pode ser atribuída a diferentes características dos milhos. No "Móleo" a maior digestibilidade deve-se possivelmente ao tamanho maior do germe observado neste tipo de grão, que possui maior teor de óleo e proteína de melhor qualidade (WATSON,
1987). No "Mdent" as características físicas do endosperma, como menor vitreosidade, é que contribuem para a maior atuação das enzimas, e conseqüentemente melhor digestibilidade dos nutrientes. Nos grãos duros (Mdur1 e Mdir2) com maior proporção de endosperma vítreo (maior vitreosidade), a alta concentração de corpos protéicos, deixa o amido relativamente indisponível para a degradação enzimática (SULLINS \& ROONEY, 1975), 
exigindo maior concentração das enzimas para digerir os grãos de características vítreas como nos grãos duros (LIMA, 2001). Esta talvez pode ser uma explicação para os valores inferiores de CDMS, CDPB, ED e \%NR que estes dois híbridos de milho apresentaram quando comparados com o milho dentado, que é mais susceptível à degradação das enzimas, em virtude de possuir menos endosperma vítreo. Em relação aos dois milhos duros, os resultados de ED não foram os esperados, pois o milho de maior vitreosidade apresentou maior valor de $\mathrm{ED}$, o que deveria ser o contrário, pensando que quanto mais vítreo o grão, menor a atuação das enzimas e menor a digestão.

\section{CONCLUSÕES}

Pode-se concluir que o milho dentado apresenta menor vitreosidade e, por isso, melhor valor nutricional, quando comparado aos híbridos semidentado e duro. Além disso, foi semelhante ou superior em alguns parâmetros nutricionais, quando comparado aos milhos "Móleo" e "MQPM", revelando seu potencial de uso para suínos.

\section{REFERÊNCIAS BIBLIOGRÁFICAS}

ASSOCIATION OFFICIAL ANALYTICAL CHEMISTS. Official methods of analysis. 18. ed. Washington, DC, 1995. 1015 p.

CORRÊA, C. E. S. Silagem de milho ou cana-de-açúcar e o efeito da textura do grão de milho no desempenho de vacas holandesas. 2001. 102 p. Tese (Doutorado em Zootecnia) Universidade Federal de Lavras, Lavras, 2001.

DOMBRINK-KURTZMAN, M. A.; BIETZ, J. A. Zein composition in hard and soft endosperm of maize. Cereal Chemistry, Saint Paul, v. 70, n. 1, p. 105-108, Jan./Feb. 1993.
FIALHO, E. T.; ROSTAGNO, H. S.; FONSECA, J. B.; SILVA, M. A. Efeito do peso vivo sobre o balanço energético e proteico de rações à base de milho e de sorgos com diferentes conteúdos de tanino para suínos. Revista da Sociedade Brasileira de Zootecnia, Viçosa, v. 8, n. 3, p. 386-397, maio/jun. 1979.

HOUSE, C. Demand for high-oil corn expected to grow rapidly. Feedstuffs, [S.1.], v. 69, n. 3, p. 1, 1997.

LIMA, G. J. M. M. Grãos de alto valor nutricional para a produção de aves e suínos: oportunidades e perspectivas. In: PRODUÇÃO ANIMAL NA VISÃO DOS BRASILEIROS, 2001, Piracicaba, SP. Anais... Piracicaba: SBZ, 201. p. 178-194.

PRATT, R. C.; PAULIS, J. W.; MILLER, K.; NELSEN, T.; BIETZ, J. A. Association of zein classes with maize kernel hardness. Cereal Chemistry, Saint Paul, v. 72, n. 2, p. 162167, 1995.

SAS INSTITUTE. SAS® user's guide: statistics. 5. ed. Cary, 1985. $1290 \mathrm{p}$.

SULLINS, R. D.; ROONEY, L. W. Ligth and scanning electron microscopy studies of waxy and nonwaxy endosperm sorghum varieties. Cereal Chemistry, Saint Paul, v. 52, n. 3, p. 361-366, May/June 1975.

WATSON, S. A. Structure and composition. In: WATSON, S. A.; RAMSTAD, P. E. (Eds.). Corn: chemistry and technology. Saint Paul: American Association Cereal Chemistry, 1987. p. 53-82. 